\title{
Correlation Study Between Preoperative Ultrasonic Features of Medullary Thyroid Carcinoma and Postoperative Recurrence
}

\section{Qiaodan Zhu}

Zhejiang Chinese Medical University

Dong Xu ( $\nabla$ xudong@zjcc.org.cn )

Cancer Hospital of the University of Chinese Academy of Sciences

\section{Research article}

Keywords: Medullary thyroid carcinoma, Ultrasound, recurrence

Posted Date: August 26th, 2020

DOI: https://doi.org/10.21203/rs.3.rs-60840/v1

License: (c) (1) This work is licensed under a Creative Commons Attribution 4.0 International License. Read Full License

Version of Record: A version of this preprint was published at BMC Cancer on April 1st, 2021. See the published version at https://doi.org/10.1186/s12885-021-07953-y. 


\section{Abstract}

Background: To investigate factors that affects postoperative recurrence in medullary thyroid carcinoma (MTC) patients in terms of preoperative ultrasonic characteristics and so on.

Method: A retrospective analysis of 74 MTC patients who underwent the first thyroid surgery from 2009 to 2018 at hospital and had complete follow-up information. According to the follow-up results, these patients were divided into recurrence group (17 cases) and non-recurrence group (57 cases). The preoperative ultrasound characteristics, preoperative and postoperative calcitonin level, and general information of the two groups were recorded separately. Univariate and multivariate analysis was performed.

Results: Single factor KM analysis showed that: $₫$ Preoperative ultrasonic characteristic of tumor size> $40.0 \mathrm{~mm}$, capsular invasion, and abnormal cervical lymph node , as well as preoperative calcitonin level > $565.8 \mathrm{pg} / \mathrm{ml}$, postoperative calcitonin (within one week) level $>45.0 \mathrm{pg} / \mathrm{ml}$ are the factors that affect postoperative recurrence of MTC $(\mathrm{P}<0.05)$; $\otimes T$ There is no evidence shows that gender and age have statistical significance with postoperative recurrence of MTC patients $(P>0.05)$. Multi-factor COX regression analysis showed that abnormal cervical lymph node $\triangle \mathrm{HR}=5.368,95 \% \mathrm{Cl} 1.063-27.104 \rrbracket \mathrm{P}=0.042 \rrbracket$ is an independent risk factor affecting postoperative recurrence of MTC patients.

Conclusions: MTC patients with abnormal cervical lymph nodes prone to postoperative recurrence. In addition, MTC patients with tumor> 40.0mm, capsular invasion, preoperative calcitonin level > 565.8pg / $\mathrm{ml}$, postoperative calcitonin level $>45.0 \mathrm{pg} / \mathrm{ml}$ are more likely to have postoperative recurrence.

\section{Background}

Medullary Thyroid Carcinoma (MTC) originates from parafollicularcell (C cell), and its incidence is only 1$2 \%$ of thyroid carcinoma [1]. Ultrasound is the first choice for thyroid disease. MTC tumors often show preoperative ultrasonic characteristics such as solidity, low echo, calcification, and clear boundaries [2-3]. Medullary thyroid carcinoma is a moderate malignant tumor with a high recurrence rate $(44.1 \%-47.3 \%)$ [4-5]. At present, researches about the factors affecting MTC recurrence mostly focus on surgical methods, calcitonin (or procalcitonin), pathology, etc. [4-6], while researches about preoperative ultrasound characteristics of MTC are relatively rare. Therefore, this study attempted to study the factors that affect the postoperative recurrence of MTC based on the preoperative ultrasonic characteristics, preoperative and postoperative calcitonin level and general information of MTC patients.

\section{Methods}

\subsection{Clinical data}

A retrospective analysis of 74 MTC patients who were admitted to the Hospital from 2009 to 2018 and had complete follow-up data. All patients underwent unilateral thyroid lobe plus isthmus excision or total 
thyroidectomy and central cervical lymph node dissection, and for those who were suspected of lateral cervical lymph node metastasis by preoperative clinical and imaging evaluation and confirmed by fine needle biopsy, lateral cervical lymph node dissection would be performed. All the patients were confirmed to be MTC by pathology.. According to the follow-up pathological results of the second operation, the cases were divided into recurrence group (17 cases, $23 \%$ ) and non-recurrence group (57 cases ,77\%). Inclusion criteria are that patients have initial thyroid surgery in our hospital, completed follow-up data, preoperative ultrasonic examination, postoperative pathological confirmation of MTC, secondary postoperative pathological confirmation of cervical lymph node recurrence. Exclusion criteria are that patients with a previous history of thyroid surgery, follow-lost patients, and cases of death. Unilateral thyroid lobe plus isthmus excision or total thyroidectomy were performed on all patients. This study was approved by the Ethics Committee of our hospital, and all patients in this study had signed informed consent forms.

\subsection{Methods}

2.2.1 Examination methods: All 74 patients underwent preoperative ultrasonic examination, using ultrasound diagnostic equipment such as Philips iU22 (L12-5 linear array probe, frequency $7.5 \sim 14 \mathrm{MHz}$ ), GE Logiq E9 (ML6-15 linear array probe, frequency $6 \sim 15 \mathrm{MHz}$ ). The patient had the supine position, head back to expose the neck, scaned and recorded the number, size, location, echo, composition, shape, boundary, aspect ratio, capsular invasion, calcification, blood flow and other information.

2.2.2 Image analysis: Two ultrasound attending physicians who have worked for more than 5 years independently analyzed the pre-stored images using the double-blind method. If the results are inconsistent, the ultrasound (associate) chief physician would be asked to assist in the analysis. Ultrasound image analysis includes the number of thyroid tumors (single focus, multiple focus), size $(\leq 40.0 \mathrm{~mm},>40.0 \mathrm{~mm}$ ), boundary (clear, unclear),composition (solid, cystic, cystic solid), morphology (regular, irregular), echo (very low echo, low echo, equal echo, high echo), aspect ratio (Front and back diameter/ Left and right diameter $\geq 1$, Front and back diameter/ Left and right diameter $\otimes 1$ ), capsular invasion (yes , no), calcification (yes, no), blood flow (rich, none) \abnormal cervical lymph node『yes, no®. If patients had multiple masses, the largest tumor was selected for analysis.

2.2.3 Collection of calcitonin: preoperative calcitonin was obtained from patients within 3 days before surgery, and postoperative calcitonin was obtained from patients within 7 days after surgery.

\subsection{Statistical analysis}

SPSS25.0 statistical software was used for statistical analysis. Measurement data is expressed as mean \pm standard deviation. The single factor K-M method was used for survival analysis, and the log-rank method was used for survival analysis. Multi-factor test uses COX regression analysis. $P<0.05$ was considered statistically significant.

\section{Results}


A total of 74 MTC patients were followed up from the date of diagnosis to November 30, 2019, with recurrence as the end event. Follow-up was 14.5 to 128.9 months, median follow-up time was 42.0 months, and 17 patients (23\%) during the follow-up period patients relapsed and the average healthy survival time was $(40.4 \pm 3.2)$ months. The $1,3,5$, and 10 years of overall healthy survival rates were $91.9 \%, 81.1 \%, 78.4 \%$, and $77.0 \%$, respectively.

\subsection{General information:}

A total of 74 MTC patients, including 42 males (56.8\%) and 32 females (43.2\%); aged 8 to 77 years, with an average of $49.6 \pm 1.6$ years. According to the postoperative pathological results, it was divided into 17 cases $(23 \%)$ in recurrence group and 57 cases (77\%) in non-recurrence group. The age (continuous variable) and recurrence (binary classification variable) were analyzed by ROC curve, and the optimal cut-

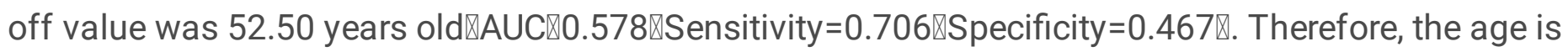
divided into $\leq 52.50$ years old and $>52.50$ years old. General data single-factor K-M survival analysis showed that there is no evidence shows that gender and age have statistical significance with the postoperative recurrence of MTC patients $(P>0.05)$. Details are shown in Table-1.

Table-1 Results of single factor K-M analysis related to recurrence of MTC patients

\begin{tabular}{|c|c|c|c|c|c|}
\hline group & character & $\begin{array}{l}\text { recurrence } \\
\text { group(cases) }\end{array}$ & $\begin{array}{l}\text { Non- recurrence } \\
\text { group(cases) }\end{array}$ & $\begin{array}{l}\text { Chi- } \\
\text { square }\end{array}$ & $\mathrm{P}$ \\
\hline \multirow[t]{2}{*}{ Gender } & male & 12 & 30 & \multirow[t]{2}{*}{1.542} & \multirow[t]{2}{*}{0.214} \\
\hline & female & 5 & 27 & & \\
\hline \multirow[t]{2}{*}{ Age } & $\leq 52.5$ & 12 & 31 & \multirow[t]{2}{*}{0.925} & \multirow[t]{2}{*}{0.336} \\
\hline & $\otimes 52.5$ & 5 & 26 & & \\
\hline \multirow{2}{*}{$\begin{array}{l}\text { Preoperative } \\
\text { calcitonin }\left(a^{\star}\right)\end{array}$} & $\leq 565.8 \mathrm{pg} / \mathrm{ml}$ & 1 & 25 & \multirow[t]{2}{*}{6.363} & \multirow[t]{2}{*}{0.012} \\
\hline & $\otimes 565.8 \mathrm{pg} / \mathrm{ml}$ & 11 & 23 & & \\
\hline \multirow{2}{*}{$\begin{array}{l}\text { Postoperative } \\
\text { calcitonin }\left(b^{\star}\right)\end{array}$} & $\leq 45.0 \mathrm{pg} / \mathrm{ml}$ & 1 & 33 & \multirow[t]{2}{*}{12.786} & 0.00349 \\
\hline & $₫ 45.0 \mathrm{pg} / \mathrm{ml}$ & 15 & 21 & & \\
\hline \multirow[t]{2}{*}{ Tumor size } & $\leq 40.0 \mathrm{~mm}$ & 13 & 53 & \multirow[t]{2}{*}{5.837} & \multirow[t]{2}{*}{0.016} \\
\hline & $\nabla 40.0 \mathrm{~mm}$ & 4 & 4 & & \\
\hline \multirow{2}{*}{$\begin{array}{l}\text { Encroachment on } \\
\text { the envelope }\end{array}$} & no & 1 & 29 & \multirow[t]{2}{*}{9.273} & \multirow[t]{2}{*}{0.002} \\
\hline & yes & 16 & 28 & & \\
\hline \multirow{2}{*}{$\begin{array}{l}\text { abnormal cervical } \\
\text { lymph nodes }\end{array}$} & no & 2 & 31 & \multirow[t]{2}{*}{8.442} & \multirow[t]{2}{*}{0.004} \\
\hline & yes & 15 & 26 & & \\
\hline
\end{tabular}


*Notes: a. 60 cases with preoperative calcitonin; b. 70 cases with postoperative calcitonin.

\subsection{Calcitonin:}

Among the 74 patients, only 60 cases had preoperative calcitonin and only 70 cases had postoperative calcitonin. The normal reference range of calcitonin was $0-10 \mathrm{pg} / \mathrm{ml}$. The range of calcitonin before surgery is $3.5-2000.0 \mathrm{pg} / \mathrm{ml}$, and the range of postoperative calcitonin is $0.5-2000.0 \mathrm{pg} / \mathrm{ml}$. Preoperative calcitonin was normal in 2 cases and elevated in 58 cases. Postoperative calcitonin was normal in 18 cases and elevated in 52 cases. The preoperative calcitonin value (continuous variable) and recurrence (binary variable) were analyzed by ROC curve, and the best diagnostic cutoff value was $565.8 \mathrm{pg} / \mathrm{ml}$ $\llbracket A U C \otimes 0.745 \llbracket$ Sensitivity $=0.917 \rrbracket$ Specificity $=0.519 \rrbracket$. There were 26 cases preoperative calcitonin $\leq 565.8 p g$ / $\mathrm{ml}$, and 34 cases $>565.8 \mathrm{pg} / \mathrm{ml}$. The ROC curve analysis of postoperative calcitonin value (continuous variable) and recurrence (binary variable) was carried out, and the best diagnostic cut-off value was $45.045 \mathrm{pg} / \mathrm{ml} \backslash \mathrm{AUC} \otimes 0.759 \bigotimes$ Sensitivity $=0.938 \bigotimes$ Specificity $=0.611 \rrbracket$. Among them, 34 cases of postoperative calcitonin $\leq 45.0 \mathrm{pg} / \mathrm{ml}, 36$ cases of $>45.0 \mathrm{pg} / \mathrm{ml}$. The single factor K-M survival analysis showed that preoperative calcitonin $>565.8 \mathrm{pg} / \mathrm{ml}$ and postoperative calcitonin $>45.0 \mathrm{pg} / \mathrm{ml}$ are the factors that affect the recurrence of MTC patients $(P<0.05)$. Details are shown in Table-1.

\subsection{Ultrasound characteristics analysis:}

$\nabla 17$ cases in recurrence group: the size of thyroid tumors under ultrasound was 8.0 to $61.0 \mathrm{~mm}$, with an average of $28.18 \pm 14.66 \mathrm{~mm}$. $\otimes 57$ cases in the non-recurrence group: the size of the thyroid tumor under ultrasound was 5.0 to $55.0 \mathrm{~mm}$, with an average of $18.68 \pm 11.57 \mathrm{~mm}$. The tumor of 74 patients was divided into $\leq 40.0 \mathrm{~mm}$ group and $>40.0 \mathrm{~mm}$ group with $40.0 \mathrm{~mm}$ as the boundary. In addition, the thyroid tumors in the recurrence group and the non-recurrence group were more characterized by single focus, solid, low echo, clear boundary, irregular morphology, aspect ratio (front and back diameter/ Left and right diameter) $<1$, calcification, and blood flow signal. The single factor K-M survival analysis showed that the tumor> $40.0 \mathrm{~mm}$, capsular invasion, and abnormal cervical lymph nodes were the survival factors affecting the recurrence of MTC patients $(P<0.05)$. Details are shown in Table-1. The corresponding ultrasonic characteristics are shown in Fig.1.However,there is no evidence shows that the number, composition, echo, boundary, morphology, aspect ratio, calcification and blood flow have statistical significance with the postoperative recurrence of MTC patients $(P>0.05)$ through single-factor K-M survival analysis. Details are shown in Table-2.

Table 2-Results 2 of single factor K-M analysis of ultrasound characteristics related to recurrence of MTC patients 


\begin{tabular}{|c|c|c|c|c|c|}
\hline group & character & $\begin{array}{l}\text { recurrence } \\
\text { group(cases) }\end{array}$ & $\begin{array}{l}\text { Non- recurrence } \\
\text { group(cases) }\end{array}$ & $\begin{array}{l}\text { Chi- } \\
\text { square }\end{array}$ & $P$ \\
\hline \multirow[t]{2}{*}{ number } & $\begin{array}{l}\text { single } \\
\text { focus }\end{array}$ & 10 & 42 & \multirow[t]{2}{*}{0.847} & \multirow[t]{2}{*}{0.357} \\
\hline & $\begin{array}{l}\text { multiple } \\
\text { focus }\end{array}$ & 7 & 15 & & \\
\hline \multirow[t]{3}{*}{ composition } & solid & 16 & 51 & \multirow[t]{3}{*}{0.605} & \multirow[t]{3}{*}{0.437} \\
\hline & $\begin{array}{l}\text { cystic } \\
\text { solid }\end{array}$ & 1 & 6 & & \\
\hline & cystic & 0 & 0 & & \\
\hline \multirow[t]{4}{*}{ echo } & $\begin{array}{l}\text { very low } \\
\text { echo }\end{array}$ & 3 & 17 & \multirow[t]{4}{*}{1.119} & \multirow[t]{4}{*}{0.773} \\
\hline & low echo & 12 & 36 & & \\
\hline & $\begin{array}{l}\text { equal } \\
\text { echo }\end{array}$ & 2 & 3 & & \\
\hline & $\begin{array}{l}\text { high } \\
\text { echo }\end{array}$ & 0 & 1 & & \\
\hline \multirow[t]{2}{*}{ boundary } & clear & 10 & 41 & \multirow[t]{2}{*}{1.370} & \multirow[t]{2}{*}{0.242} \\
\hline & unclear & 7 & 16 & & \\
\hline \multirow[t]{2}{*}{ morphology } & regular & 4 & 26 & \multirow[t]{2}{*}{2.609} & \multirow[t]{2}{*}{0.106} \\
\hline & irregular & 13 & 31 & & \\
\hline \multirow{2}{*}{$\begin{array}{l}\text { aspect ratio } \\
\text { (Front and back diameter/ } \\
\text { Left and right diameter) }\end{array}$} & $\geq 1$ & 2 & 5 & \multirow[t]{2}{*}{0.023} & \multirow[t]{2}{*}{0.881} \\
\hline & $\nabla 1$ & 15 & 52 & & \\
\hline \multirow[t]{2}{*}{ calcification } & yes & 12 & 36 & \multirow[t]{2}{*}{0.525} & \multirow[t]{2}{*}{0.469} \\
\hline & no & 5 & 21 & & \\
\hline \multirow[t]{2}{*}{ blood flow* } & yes & 12 & 38 & \multirow[t]{2}{*}{0.337} & \multirow[t]{2}{*}{0.562} \\
\hline & no & 2 & 11 & & \\
\hline
\end{tabular}

*Notes: Only 63 patients with ultrasonic figure of blood flow.

\subsection{Multi-factor COX regression analysis:}

3 ultrasonic characters were used to construct a multi-factor COX regression equation, including the size of the tumor, capsular invasion, and the abnormal cervical lymph nodes. As a result, abnormal cervical 
lymph nodes $₫ \mathrm{HR}=5.368,95 \% \mathrm{Cl} 1.063-27.104 \otimes \mathrm{P}=0.042 \rrbracket$ was $\mathrm{MTC}$ patient's independent risk factor for recurrence. Details are shown in Table-3.

\section{Table-3 Multi-factor COX regression analysis results}

\begin{tabular}{|llccll|}
\hline group* & B & Degree of freedom & P & HR & $95 \% \mathrm{Cl}$ \\
\hline Tumor size & 0.853 & 1 & 0.153 & 2.347 & $0.728-7.570$ \\
\hline Capsular invasion & 2.181 & 1 & 0.050 & 8.855 & $0.996-78.730$ \\
\hline Abnormal cervical lymph nodes & 1.680 & 1 & 0.042 & 5.368 & $1.063-27.104$ \\
\hline
\end{tabular}

* Note: tumor Size ( 1 is $\leq 40.0 \mathrm{~mm}, 2$ is $>40.0 \mathrm{~mm}$ ), Capsular invasion ( 0 no, 1 yes), abnormal lymph nodes in the neck (0 no, 1 yes).

\section{Discussion}

MTC accounts for an extremely small proportion of thyroid carcinoma and is a moderate malignant carcinoma, and for it is derived from C cells, its biological characteristics and malignant degree differ from other types of thyroid carcinoma derived from thyroid follicular cells. MTC is prone to recurrence after operation. In this study, the recurrence rate after MTC reached $23 \%(17 / 74)$, which was lower than the recurrence rate reported in the previous literature (44.1\% -47.3\%) [4-5].

In terms of general information, through univariate analysis, Zhang Zaixing et al [6] fund that gender (female) and age ( $\geq 45$ years) were important factors affecting survival (recurrence, death, etc.) $(P<0.05)$. Through multifactorial analysis, Hassan et al. [4] found that gender(male) was the poor prognostic factors (recurrence, death, etc.) of MTC patients $(P<0.05)$. In this study, the recurrence group and the nonrecurrence group were more often to be male and young ( $\leq 52.5$ years old), and there was no statistical significance between gender, age and recurrence $(P>0.05)$. The conclusions obtained in this study are partially consistent and partially contradictory with the conclusions of the above studies, which are related to the different definitions of the ending of the three studies and the small number of cases.

MTC is derived from C cells that secrete calcitonin, so it has the characteristic expression of elevated calcitonin. Some studies have found that patients with MTC who still have elevated postoperative calcitonin were more prone to have cervical lymph node metastasis and recurrence [7]. Through multivariate analysis, Hassan et al. [4] found that MTC patient's postoperative calcitonin doubling time less than two years and that the rate of increase in calcitonin value greater than $0.05 \mathrm{pg} / \mathrm{ml} / \mathrm{month}$ were poor prognostic factors $(P<0.05)$. A study through meta-analysis showed that procalcitonin can be used as a marker for postoperative follow-up monitoring of MTC patients to monitor recurrence [5]. In this study, single factor KM survival analysis showed: preoperative calcitonin>565.8pg / ml, postoperative calcium Factors $>45.0 \mathrm{pg} / \mathrm{ml}$ are factors that affect the recurrence of MTC patients $(P<0.05$, see Table- 1$)$. Only 60 cases had preoperative calcitonin and only 70 cases had postoperative calcitonin, so they were 
not included in the multivariate analysis. The conclusion that there is statistical significance between the elevated calcitonin (or procalcitonin) and the recurrence of MTC patients is not new, and the specific values of calcitonin (or procalcitonin) that affect recurrence are not the same in each study. This is related to the limited number of cases enrolled in various studies, the large age span, and different test levels.

Starting from the ultrasonic features of medullary thyroid carcinoma, the research on exploring the relationship between MTC and cervical lymph node metastasis is relatively extensive, while there are relatively few studies on the relationship between preoperative ultrasonic features and recurrence of MTC. Studies have pointed out that in sporadic medullary thyroid carcinoma, single-factor chi-square analysis believes that patients with tumors $>15 \mathrm{~mm}$, irregular morphology, sharp edges, and masses located under the capsule have a higher risk of lateral neck lymph node metastasis $(P<0.05)$ [8]. The ultrasound characteristics of medullary thyroid carcinoma mass include the size, number, echo, composition, boundary, morphology, invasion of the capsule, aspect ratio, calcification, blood flow, etc. In this study, single factor KM analysis showed that the tumor $40.0 \mathrm{~mm}$, capsular invasion, and abnormal cervical lymph nodes were the survival factors affecting the recurrence of MTC patients $(P<0.05)$. These three factors represent the size of the tumor, the relationship with the surrounding adjacent tissues, and the status of the lymph nodes, which can be further applied to the preoperative T and N stages of MTC patients. Some studies have shown that T4 is a poor prognostic factor through multi-factor analysis [4], and some studies have shown that TNM staging is a factor affecting prognosis through single factor analysis [6]. The results of the multi-factor COX regression analysis in this study showed that abnormal cervical lymph node was the only independent risk factor affecting the recurrence of MTC patients. In addition, this study found that in the recurrence group and the non-recurrence group, the tumors were mostly characterized by solidity, low echo, clear boundaries, and calcification. There were no statistically significant differences between the ultrasound features such as the composition, echo, boundary, calcification and recurrence of MTC patients.

In this study, the results of univariate $\mathrm{KM}$ analysis showed that: tumor> $40.0 \mathrm{~mm}$, capsular invasion, abnormal cervical lymph nodes, preoperative calcitonin $>565.8 \mathrm{pg} / \mathrm{ml}$, postoperative calcitonin $>45.0$ $\mathrm{pg} / \mathrm{ml}$ are the effects factors of MTC recurrence $(P<0.05)$. The results of multi-factor COX regression analysis showed that abnormal cervical lymph node $\triangle \mathrm{HR}=5.368,95 \% \mathrm{Cl} 1.063-27.104 \otimes \mathrm{P}=0.042 \rrbracket$ is independent risk factors affecting the recurrence of MTC patients. MTC patients with abnormal cervical lymph nodes are more likely to relapse. Calcitonin was not included in the multivariate analysis, but to a certain extent, preoperative calcitonin $>565.8 \mathrm{pg} / \mathrm{ml}$, postoperative calcitonin $>45.0 \mathrm{pg} / \mathrm{ml}$ can also indicate more likely to relapse.

In this study, a total of 74 patients with MTC, including 17 cases of recurrence during follow-up, 57 cases of non-recurrence, and 2 death cases were not included in the study. The conclusion of this study is that the ultrasound features can be used for preoperative $\mathrm{T}$ and $\mathrm{N}$ staging, but no factors related to recurrence have been found from other ultrasound features such as the composition, echo, boundary, and calcification. At the same time, the number of recurrence cases in this study did not reach half of the total 
number of cases, and the median survival time could not be obtained in the K-M survival analysis. The follow-up study can be continued in the future.

\section{Abbreviations}

MTC『medullary thyroid carcinoma

C cell囚parafollicularcell

\section{Declarations}

\subsection{Ethics approval and consent to participate}

This study was approved by the Ethics Committee of our hospital, and all patients in this study had signed informed consent forms. In this study, written informed consent for participation was obtained where participants are children (under 16 years old) from their parent or guardian.

\subsection{Consent for publication}

This study was approved by our hospital for publication.

\subsection{Availability of data and material}

I can confirm I have included a statement regarding data and material availability in the declaration section of my manuscript.

\subsection{Competing interests}

We have no competing interests in the work.

\subsection{Funding}

This work was supported by the National Natural Science Foundation of China[grant number 81871370]; and the Natural Science Foundation of Zhejiang Province (CN) [grant number LSD19H180001].

\subsection{Authors' contributions}

We certify that we have participated sufficiently in the work to take public responsibility for the appropriateness of the experimental designs and methods, and the collection, analysis, and interpretation of the data.

\subsection{Acknowledgements}

Not applicable. 


\section{References}

1. Wells S A, Asa S L , Dralle H, et al. Revised American Thyroid Association Guidelines for the Management of Medullary Thyroid Carcinoma[J]. Thyroid, 2015, 25(6):567-610. https://doi.org/10.1089/thy.2014.0335

2. Cai S,Ouyang YS,Li JC, et al. Role of Ultrasonography in the Diagnosis of Medullary Thyroid Carcinoma[J].CHINESE JOURNAL OF ULTRASOUND IN MEDICINE, 2008, 24(12):1071-1075. (Chinese article) DOIIhttps://doi.org/10.3969/j.issn. 1002-0101.2008.12.005

3. Bao SD,Pang P,Zang $L$, et al. Predictive value of sonographic features in preoperative evaluation of medullary thyroid carcinoma[J]. National Medical Journal of China, 2016, 96(31):2482-2486. (Chinese article) DOI $10.3760 /$ cma.j.issn.0376-2491.2016.31.009

4. Hassan A, Siddique M, Riaz S, et al. Medullary Thyroid Carcinoma: Prognostic Variables And Tumour Markers Affecting Survival[J]. Journal of Ayub Medical College, Abbottabad $₫ 2018 ; 30$ (Suppl 1) (4):S627-S632. PMID: 30838820

5. Pierpaolo T, Luca G . Procalcitonin as Marker of Recurrent Medullary Thyroid Carcinoma: A Systematic Review and Meta-Analysis[J]. Endocrinology \& Metabolism, 2018, 33(2):204-. DOI] 10.3803/EnM.2018.33.2.204

6. Zhang ZX,Li ZJ,Tang PZ, et al. Surgical treatment and prognosis analysis on medullary thyroid carcinoma[J]. Chinese Journal of Otorhinolaryngology Head and Neck Surgery, 2011(3):209-213. (Chinese article) PMID: 21575412

7. Cho K E , Gweon H M , Park A Y, et al. Ultrasonographic Features of Medullary Thyroid Carcinoma: Do they Correlate with Pre and PostOperative Calcitonin Levels?[J]. asian pac j cancer prev, 2016, 17(7):3357-3362. PMID: 27509975

8. Oh H S , Kwon H, Song E, et al. Preoperative Clinical and Sonographic Predictors for Lateral Cervical Lymph Node Metastases in Sporadic Medullary Thyroid Carcinoma[J]. Thyroid, 2018:thy.2017.0514. DOI $10.1089 /$ thy.2017.0514

\section{Figures}



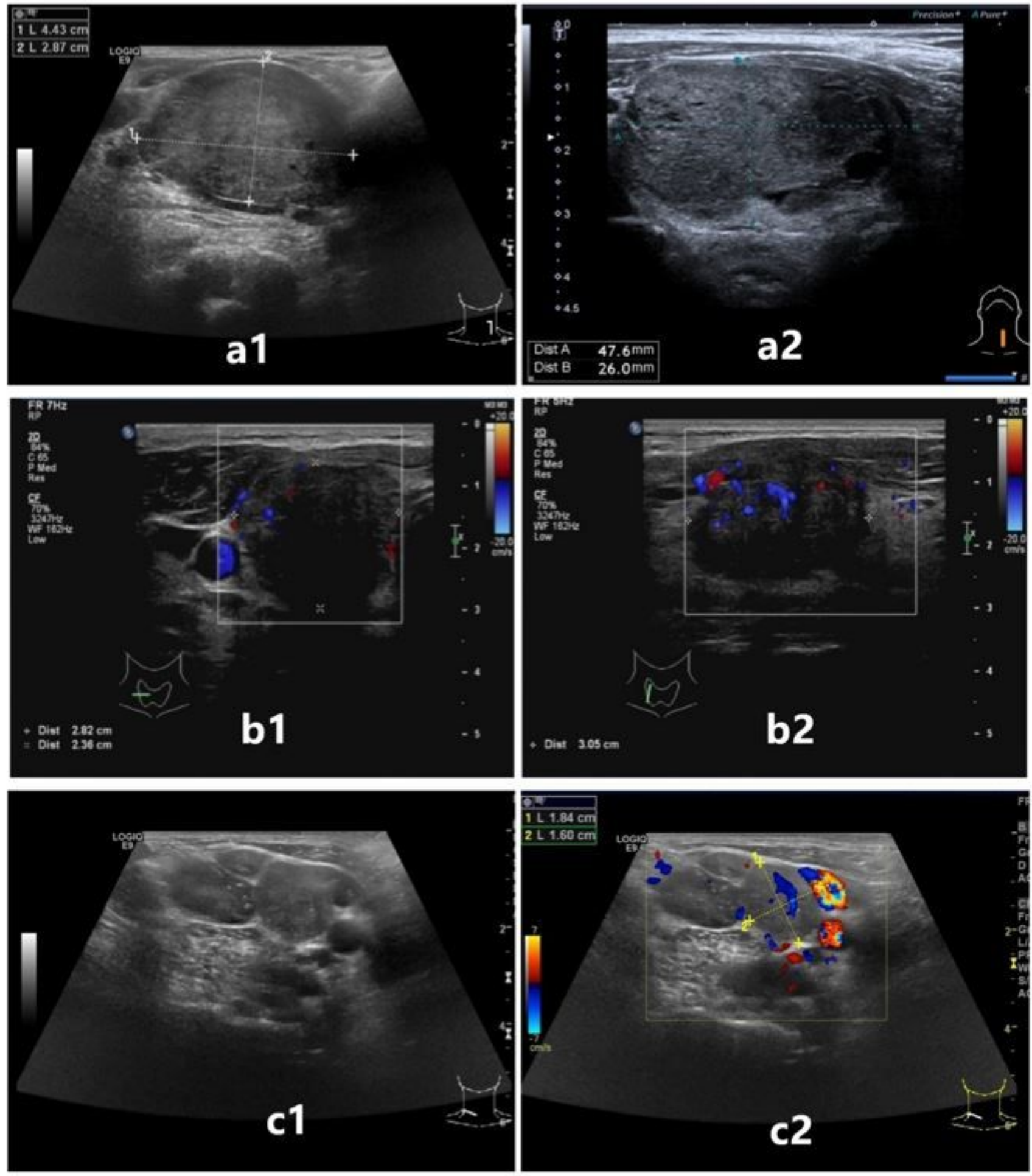

\section{Figure 1}

Ultrasonic characteristics of the MTC tumor: a1 and a2 show tumor size $>40.0 \mathrm{~mm}$; b1 and b2 show capsular invasion; $\mathrm{c} 1$ and c2 show abnormal cervical lymph nodes. 